\title{
Understanding the Reliability of Localized Near Future Weather Data for Building Performance Prediction in the UK
}

\author{
$\mathrm{Hu} \mathrm{Du}$ and Phil Jones \\ Welsh School of Architecture \\ Cardiff University \\ Cardiff, United Kingdom \\ duh4@cardiff.ac.uk
}

\author{
Bobo $\mathrm{Ng}$ \\ Department of Mechanical and Construction Engineering \\ Northumbria University \\ Newcastle upon Tyne, United Kingdom
}

\begin{abstract}
Access to reliable site-specific near future weather data is crucial for forecasting temporally-dynamic building energy demand and consumption, and determining the state of on-site renewable energy generation. Often there is a missing link between weather forecast providers and building energy management systems. This short paper discusses the potential to conduct building performance modelling using localized high resolution weather forecast freely available from the United Kingdom Met Office DataPoint service. It creates a great opportunity for building performance simulation professionals and building energy managers to re-use site-specific high resolution weather forecast data to predict near future building performance at both individual building and city scale. In this paper, authors have developed a framework of forecasting near future building performance and a Matlab script to automatically gather observed weather data from 140 weather stations and weather forecasts for nearly 6,000 locations in the UK. To understand the reliability of weather forecast, threehourly forecasts of temperature, relative humidity, wind speed and wind direction are compared with observations from weather stations. This provides evidences to use the next 24-hour forecast to predict dynamic building energy demand and consumption, and determine the on-site renewable energy generation output. Because of the high accuracy of forecast, the rolling forecast can be recorded on daily basis to construct weather files for locations that do not have weather stations. This will increase current 14 locations of the CIBSE weather data to nearly 6,000 locations covering population centers, sporting venues and tourist attractions.
\end{abstract}

Keywords-building performance prediction; near future weather data; Met Office; DataPoint; wind speed;

\section{INTRODUCTION}

The European Energy Efficiency Directive establishes a set of binding measures in 2012 to help the EU reach its $20 \%$ energy efficiency target by 2020[1]. Under the Directive, all EU countries are required to use energy more efficiently at all stages of the energy chain from its production to its final consumption. Smart building energy demand response solutions considering weather forecasts enable end users to reduce energy bills, improve their thermal comfort conditions, increase the efficiency of energy grid and contribute to the

This study is part of the Ser Cymru ('Stars Wales' in English) program funded by the Welsh government. integration of renewable energy. A recent review by Lazo et al. [2] shows that the optimization of energy management with weather forecasting can generate $15-30 \%$ savings in most cases. At the individual building level, the use of both thermal and electric loads prediction technologies with weather forecast could optimize energy demand, storage and supply, and reduce the building response time, thus reducing costs and greenhouse gas emissions. At city scale, high-accuracy multi-point weather forecasts can reflect the real environment at urban condition such as considering urban heat island effects, therefore it increases the accuracy of performance prediction in real life urban conditions.

Access to reliable site-specific near future weather data is crucial for all the works mentioned above. Often there is a missing link between weather forecast provider and building energy management system. This short paper discusses the potential to conduct building performance prediction using localized high resolution weather forecast.

\section{A. Weather data for building performance prediction}

Appropriate meteorological data are needed for predicting annual performance of energy systems. This led to the development of so-called Typical Meteorological Year (TMY) data in the USA, or a term of Test Reference Years (TRY) mainly used in Europe [3]. TMY data provides building simulation professionals with a reasonably sized annual data set that holds hourly meteorological values for a specific location.

In the USA, the TMY data set is composed of 12 typical meteorological months (January through December) that are concatenated essentially without modification to form a single year. The 12 selected typical months for each station were chosen using the Finkelstein-Schafer statistic method[4], which considering the combination of global horizontal solar radiation, dry bulb temperature, direct normal solar radiation, wind speed and dew point temperature, which are the important variables for building performance simulation.

In the UK, the Chartered Institution of Building Services Engineers (CIBSE) developed TRY and Design Summer Year (DSY) data sets for 14 cities in the UK. The selection of typical 
months applied by the CIBSE is similar to the selection procedure of TMY data, however it only applies to dry bulb temperature, global horizontal solar radiation and wind speed. The DSY data, which consists of an actual 1-year sequence of hourly data, are selected based on dry bulb temperatures during the period April-September only. This enables designers to simulate building performance for a year with a hot, but not extreme, summer.

\section{B. Weather stations}

Comparing with the 14 locations of CIBSE weather data, the Met office has access to 140 observation weather stations in the UK (shown in Fig 1 left). If all data are available to building professionals in a right format, there is a potential to reduce the distance between the location of the building to be modeled and the location of weather data used for modeling, from hundreds of kilometers to tens of kilometers. However, currently the full set observation data from all 140 weather stations are only available to few research institutes and they are not in a ready-to-use format that can be fed into building simulation programs directly.

Often the 140 weather stations are located outside the cities and they are still tens of kilometers away from the real location of the buildings to be studied in most of cases. For example, for buildings in the center of London, Heathrow or Gatwick airport weather data is used for simulation. In the real life environment, the temperature difference between the two locations could be up to $10{ }^{\circ} \mathrm{C}$ [5] due to urban heat island effect and micro-climate. Increasing the number and density of weather stations could potentially increase the accuracy of building simulation, however it is often limited by its cost and time for data collection. Typically it needs 20-30 years recorded data to produce a set of TRY/TMY data. Therefore there is a need to consider the alternative source of weather data for building simulation.

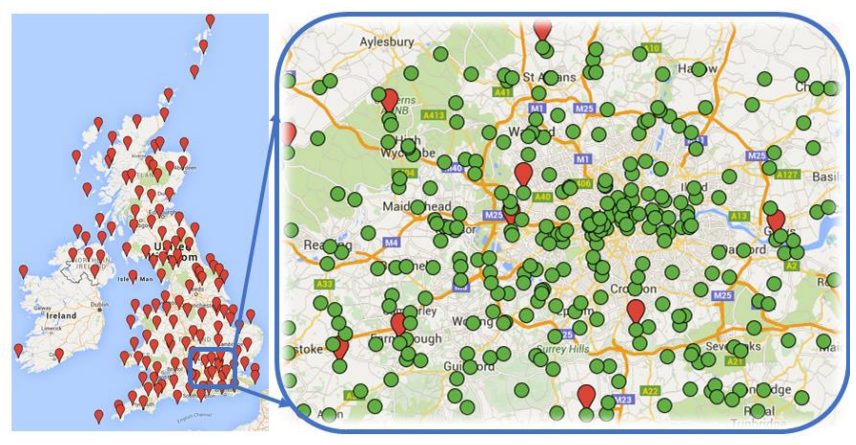

Fig. 1. 140 observation stations in the UK (red dots) and around 300 sites near London having weather forecast data (green dots)

\section{The UK Met Office Weather forecast}

Forecasting weather involves predicting future variations in a complex system. The UK Met Office started making regularly use of numerical method to forecast weather in 1959. The advances in technology, such as the recent Cray XC40 supercomputer, and better understanding of weather events have helped them to deliver huge improvements in forecasting accuracy over recent decades. Today's Met Office forecasts out to four days are as accurate as their one-day forecasts were 30 years ago[6], and the horizontal resolution of their forecast has been increased to $1.5 \mathrm{~km}$ in 2010 from $150 \mathrm{~km}$ in 1990 .

\section{Data sharing Application Programming Interface}

As part of the UK Government's Open Access movement, the Met Office is working towards making the data available to the public. Since 2011, the Met Office released 3-hourly sitespecific forecast data feeds for nearly 6,000 locations in the UK, which covers population centers, sporting venues and tourist attractions, through the Met Office DataPoint service [7]. The DataPoint service is an Application Programming Interface (API) that provides last 24-hour land and marine observations, lightning strikes frequency map, monthly regional climate anomalies, historic regional climate data and more importantly 3-hourly weather forecast for next 5 days. The files from the DataPoint are in a format of Extensible Markup Language (XML) which is suitable for web application developers to use. Forecasts are regularly updated on hourly basis and make use of a range of weather models run on the Met Office's supercomputer.

The high spatial resolution forecast has significantly increased the density of weather data locations comparing with traditional 140 observation stations. For example, weather forecasts are made available for around 300 locations near London (shown in green dots in Fig 1 right) from the DataPoint service, comparing with only 10 observation stations (in red dots). This provides a great opportunity for building performance simulation professionals to re-use the Met Office data for predicting near future building performance. It reduces the distance between the location of building and the location of weather data from tens of kilometers to several kilometers or meters, therefore it increases the accuracy of building performance prediction.

\section{THE CHALLENGES AND RESEARCH METHOD}

Based on the skill sets and availability of recourses, the authors proposed the following framework (illustrated in Fig 2) for predicating near future building thermal performance and energy consumption using DataPoint, Matlab and EnergyPlus.

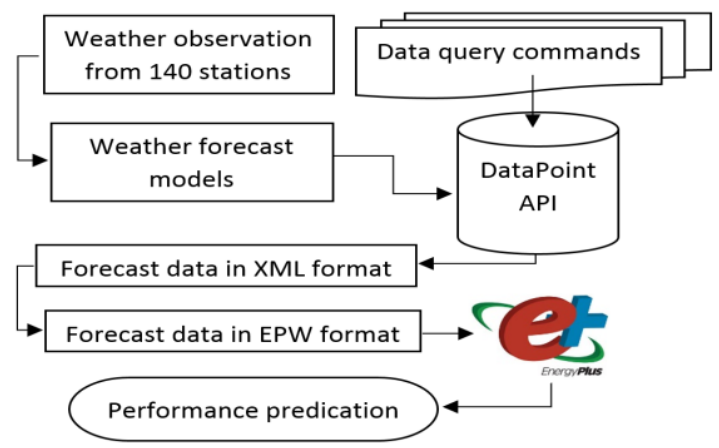

Fig. 2. The proposed framework for near future building performance predication

Due to the paper limit, the alterative frameworks, programming language and simulation engines are not 
discussed here. For early stage research, the combination of tools above has been proved to be efficient at lab condition.

At current stage of research, there are three main challenges in making use of the Met Office DataPoint site-specific forecast data for building performance prediction:

- Automatically collecting forecast and observation data on regular basis.

- Converting the collected Extensible Markup Language (.xml) weather files into a format suitable for building simulation professionals.

- Understanding the reliability of localized forecast for building performance modelling. This was not possible until large sets of site-specific forecasts were made available to the public. It is a common practice to understand the reliability when dealing with unknown large data sets.

In previous research [8], authors have tackled the first two challenges by developing a method of collecting weather forecast data for nearly 6000 locations and observation data from 140 weather stations in the UK through the Met Office DataPoint service API. The method has been successfully translated into a Matlab script to automatically gather data on daily basis because of the rolling updates of weather forecast. The Matlab script could capture the latest weather forecast and stored on a local computer for future use. This short paper particularly focuses on the third challenge - to understand the reliability of forecast for building performance modeling. The following research method has be employed:

- Develop a checklist of weather parameters available in forecast and observation XML files and identify the difference and additional parameters needed for building performance prediction.

- Compare key common weather parameters existed in both forecast and observation files and quantify the difference.

\section{EARLY RESEARCH RESULTS}

\section{A. Parameters available from DataPoint API}

The Met Office DataPoint API outputs (XML files) follow a defined rules for encoding documents in a format which is both human-readable and machine-readable. As illustrated in Table 1, a range of weather related parameters are available in these files. Note that sea level pressure, pressure tendency and dew point temperature exist in the observation file, but not in forecast file. Solar UV Index, Precipitation Probability, Feels Like Temperature are only available from forecasts, not from observations. A key weather parameter for building performance modeling - solar radiations (including global, direct and diffuse) are missing from both files.

The following results section compared the forecast and observation of temperature, relative humidity, wind speed and wind direction which exists in both files (highlighted in grey in Table 1). The comparisons were made using data of December 2015, London Heathrow which has a dedicated weather station.
TABLE I. WEATHER PARAMETERS IN THE FORECAST AND OBSERVATION XML FILES

\begin{tabular}{|c|c|c|c|c|}
\hline Symbol & Description & Forecast & Observation & Unit/Notes \\
\hline$i$ & Location ID & $\sqrt{ }$ & $\sqrt{ }$ & I \\
\hline lat & Latitude & $\sqrt{ }$ & $\sqrt{ }$ & degree \\
\hline lon & Longitude & $\sqrt{ }$ & $\sqrt{ }$ & degree \\
\hline$W$ & Weather type & $\sqrt{ }$ & $\sqrt{ }$ & $0-30$ \\
\hline$T$ & Temperature & $\sqrt{ }$ & $\sqrt{ }$ & ${ }^{\circ} \mathrm{C}$ \\
\hline $\boldsymbol{H}$ & $\begin{array}{l}\text { Relative } \\
\text { humidity }\end{array}$ & $\sqrt{ }$ & $\sqrt{ }$ & $\%$ \\
\hline$S$ & Wind speed & $\sqrt{ }$ & $\sqrt{ }$ & $\mathrm{mph}$ \\
\hline$D$ & Wind direction & $\sqrt{ }$ & $\sqrt{ }$ & $\begin{array}{l}\text { 16-point } \\
\text { compass } \\
\text { direction }\end{array}$ \\
\hline$G$ & Wind Gust & $\sqrt{ }$ & $\sqrt{ }$ & $\mathrm{mph}$ \\
\hline$P$ & $\begin{array}{l}\text { Sea level } \\
\text { pressure }\end{array}$ & & $\sqrt{ }$ & $\mathrm{hPa}$ \\
\hline$V$ & Visibility & $\sqrt{ }$ & $\sqrt{ }$ & $\mathrm{m}$ \\
\hline$P t$ & $\begin{array}{l}\text { Pressure } \\
\text { Tendency }\end{array}$ & & $\sqrt{ }$ & $\begin{array}{c}\text { F, Falling; R } \\
\text { Rising, S Steady }\end{array}$ \\
\hline$D p$ & $\begin{array}{l}\text { Dew point } \\
\text { temperature }\end{array}$ & & $\sqrt{ }$ & ${ }^{\circ} \mathrm{C}$ \\
\hline$U$ & Solar UV Index & $\sqrt{ }$ & & $1-11$ \\
\hline$P p$ & $\begin{array}{c}\text { Precipitation } \\
\text { Probability }\end{array}$ & $\sqrt{ }$ & & $\%$ \\
\hline $\boldsymbol{F}$ & $\begin{array}{c}\text { Feels Like } \\
\text { Temperature }\end{array}$ & $\sqrt{ }$ & & ${ }^{\circ} \mathrm{C}$ \\
\hline & $\begin{array}{c}\text { Wet bulb } \\
\text { temperature }\end{array}$ & \multicolumn{2}{|c|}{ Missing } & $\begin{array}{l}\text { Linked to other } \\
\text { parameters }\end{array}$ \\
\hline & Solar radiation & \multicolumn{2}{|c|}{ Missing } & Related to others \\
\hline
\end{tabular}

\section{B. Temperature}

Figure 3 shows the small difference between observed 3hourly temperature and the forecast (general less than 1 degree

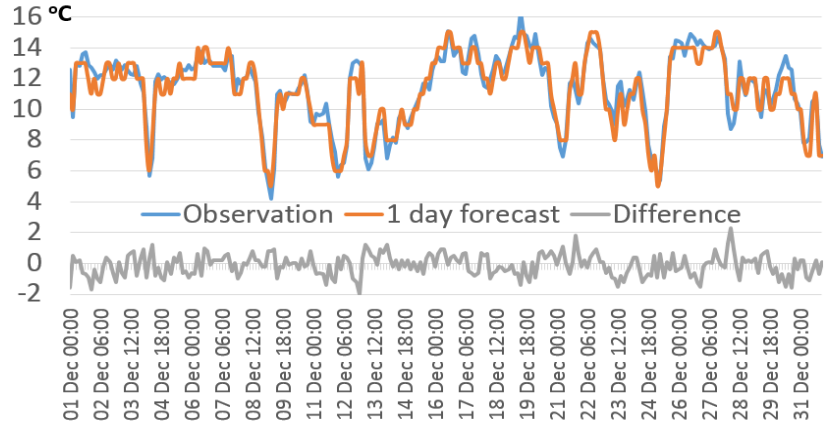

Fig. 3. Temperature Forecast vs. Observation, Dec2015 Heathrow

Celsius). Note that the forecast is constructed with the most recent 24-hour forecast (a rolling forecast over that month). The observations were taken from Met Office weather stations.

\section{Relative humidity}

The same format of comparison was made for relative humidity in Figure 4. Forecasts generally follow observations with a difference of less than $10 \%$ in general.

\section{Wind speed}

The forecast wind speeds also closely follow observations (shown in Figure 5). The differences are generally less than 5 miles per hour. 


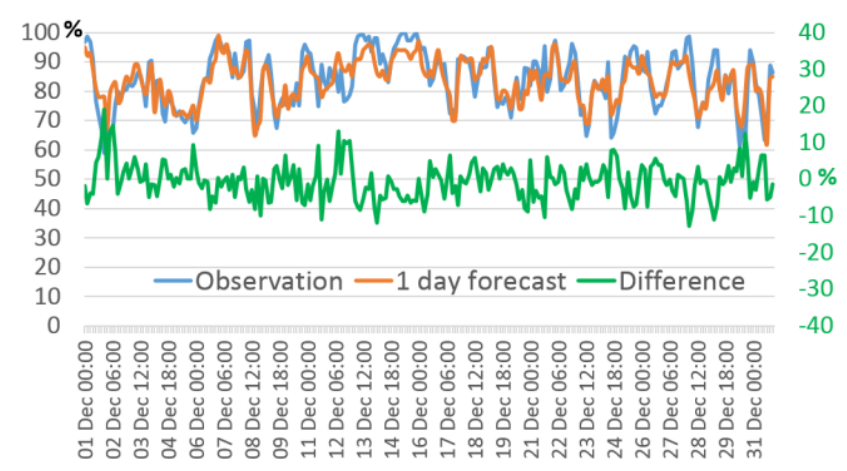

Fig. 5. Relative Humidity Forecast vs. Observation, Dec2015 Heathrow

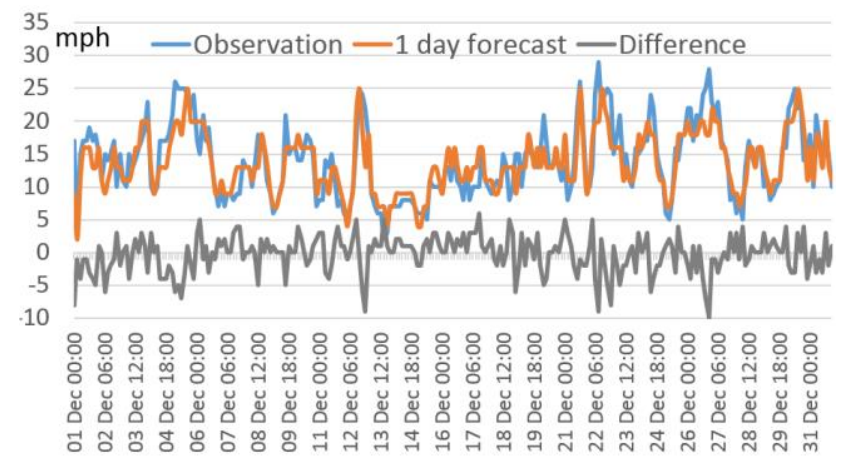

Fig. 4. Wind Speed Forecast vs. Observation, Dec2015 Heathrow

\section{E. Wind direction}

Both forecast and observation of wind direction use 16 point compass as unit. In order to compare the data, the text descriptions of wind direction have been converted to values in range of 0-360 degree. The results (Figure 6) shows that forecasts are very close to observations.

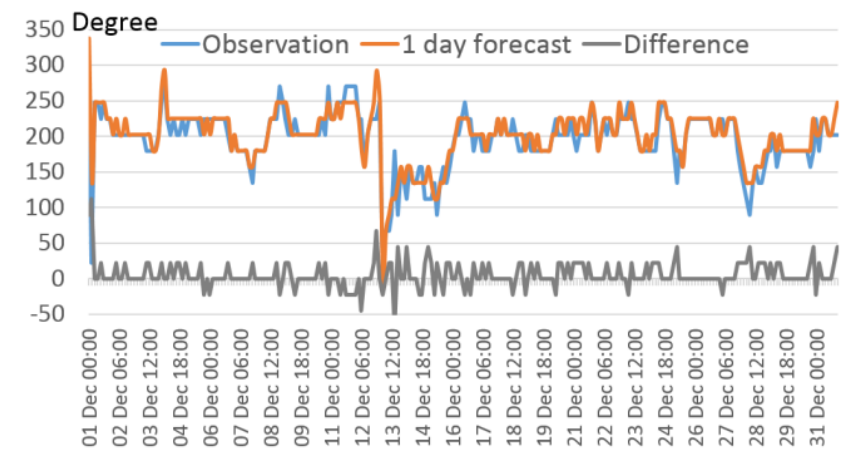

Fig. 6. Wind Direction Forecast vs. Observation, Dec2015 Heathrow

Further analysis has been conducted to quantify the distribution (Figure 7) of the differences between forecasts and observations. The results are in line with previous findings that 1-day ahead forecasts of temperature, relative humidity, wind speed and direction are very close to observations. Due to the page limit, study for longer period, other locations and comparisons at urban/rural environment will be reported in a journal paper.

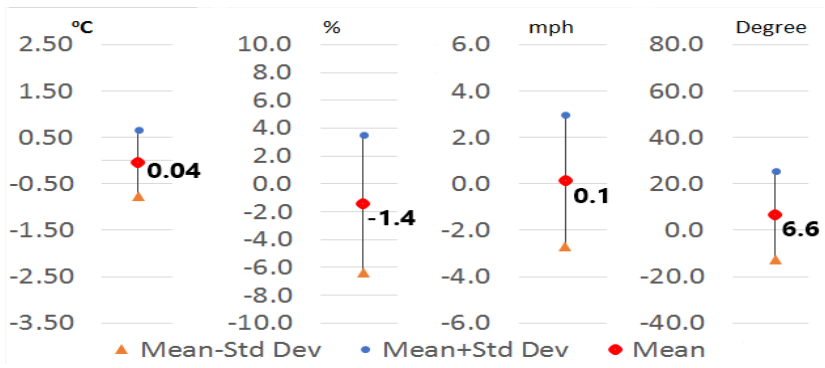

Fig. 7. Mean and standard deviations of the differences between forecasts and observations, December 2015, Heathrow

\section{CONCLUSION}

Through the detailed comparison of 4 observed weather parameters and their forecasts, the authors understood the accuracy of near future weather forecast. This provided confidence in creating 'true' weather data for locations that do not have weather observation stations. The work also provided evidences to use the next 24-hour forecast to predict dynamic building energy demand and consumption, and determine the state of on-site renewable energy generation.

Future work will focus on urban scale building energy management using high spatial resolution forecast data, urban heat land effect study and site-specific renewable energy generation prediction.

\section{ACKNOWLEDGMENT}

The authors thankfully acknowledge the DataPoint service provided by the UK Met Office. The authors also would like to thank W. Falkena at Delft University of Technology and others for sharing the 'xml2struct.m' Matlab function.

\section{REFERENCES}

[1] European Parliament and Council, "Directive 2010/31/EU of the European parliament and of the council on the energy performance of buildings," Official Journal of the European Union, vol. L, pp. 13-35, 2010.

[2] D. Lazos, A. B. Sproul, and M. Kay, "Optimisation of energy management in commercial buildings with weather forecasting inputs: A review," Renewable and Sustainable Energy Reviews, vol. 39, pp. 587$603,11 / / 2014$.

[3] A. Argiriou, S. Lykoudis, S. Kontoyiannidis, C. A. Balaras, D. Asimakopoulos, M. Petrakis, et al., "Comparison of methodologies for tmy generation using 20 years data for Athens, Greece," Solar Energy, vol. 66, pp. 33-45, 1999.

[4] G. J. Levermore and J. B. Parkinson, "Analyses and algorithms for new Test Reference Years and Design Summer Years for the UK," Building Service Engineering, vol. 27, pp. 311-325, November 12006.

[5] M. Santamouris, N. Papanikolaou, I. Livada, I. Koronakis, C. Georgakis, A. Argiriou, et al., "On the impact of urban climate on the energy consumption of buildings," Solar Energy, vol. 70, pp. 201-216, // 2001.

[6] Met Office. (2016). Developing the science for long range weather forecasts. Available: http://www.metoffice.gov.uk/news/in-depth/longrange-forecasting

[7] Met Office. (2016). Met Office DataPoint. Available: http://www.metoffice.gov.uk/datapoint

[8] H. Du, P. Jones, and S. Lannon, "Creating localised near future weather data for predicting the performance of buildings in the UK," in Clima 2016 -12th REHVA World Congress, Aalborg, Denmark, 2016. 